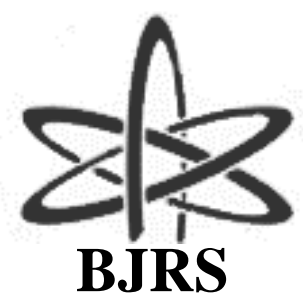

\author{
BRAZILIAN JOURNAL \\ $\mathrm{OF}$ \\ RADIATION SCIENCES \\ 07-2A (2019) 01-18
}

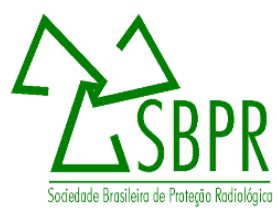

\title{
Establishing adequate conditions for mercury determination in environmental samples by INAA
}

\author{
C. Perez; E. C. Santos; M. Saiki \\ Instituto de Pesquisas Energéticas e Nucleares (IPEN - CNEN/SP), 05508-000, São Paulo, SP, Brazil \\ caroline.perez@usp.br
}

\begin{abstract}
Mercury $(\mathrm{Hg})$ is a toxic element released into the environment mainly by anthropic activities. Consequently, the improvement for Hg determination in environmental samples is of great interest. Instrumental Neutron Activation Analysis (INAA) is considered an adequate method to determine several elements. However, Hg determination by INAA is often hampered by its volatility, which causes losses, depending on the local temperature in the reactor where the sample is irradiated. The aim of this study was to establish adequate irradiation conditions in the IEA-R1 reactor for $\mathrm{Hg}$ determination in environmental samples by INAA. The following parameters were evaluated: irradiation time, container for irradiation and spectral gamma ray interferences. For the study, aliquots of certified reference materials (CRMs) and tree bark samples were irradiated together with $\mathrm{Hg}$ synthetic standard at the IEA-R1 nuclear research reactor. Gamma ray activities of ${ }^{197} \mathrm{Hg}$ and ${ }^{203} \mathrm{Hg}$ were measured in a spectrometer coupled to a HPGe detector. Obtained results indicated that polyethylene capsules or envelopes can be used as container for sample irradiation and the $\mathrm{Hg}$ impurities in these containers were negligible. Irradiation time of one hour was adequate for $\mathrm{Hg}$ determination and in long irradiations of $8 \mathrm{~h}$ problems of spectral interference of ${ }^{198} \mathrm{Au}$ and ${ }^{75} \mathrm{Se}$ were observed. In addition, $\mathrm{Hg}$ loss during the irradiation of $1 \mathrm{~h}$ and after irradiation was not observed. Quality control of $\mathrm{Hg}$ results, obtained in the CRMs analyses using one hour of irradiation, indicated good precision and accuracy with HORRAT $<2$ and $\mid \mathrm{Z}$ score $\mid<2$. The experimental conditions established in this study were applied to tree bark samples. Detection limits in these analyses were between 0.14 and $1.9 \mu \mathrm{g} \mathrm{g}^{-1}$.

Keywords: Mercury, INAA, environmental samples.
\end{abstract}




\section{INTRODUCTION}

Mercury $(\mathrm{Hg})$ is a toxic element that causes adverse effects on human health and on the environment, arousing much concern everywhere due to its volatility, persistence and bioaccumulation [1]. Its toxicity depends on its chemical form, concentration, route of exposure and the exposed individual's vulnerability [2]. Mercury is emitted into the atmosphere by various anthropic activities, such as coal-fired power plants, mining activities, waste incineration and industrial processes used in foundries and cement production [3]. Consequently, it is of great interest to improve analytical methods for the quantification of this element in environmental samples.

Instrumental neutron activation analysis (INAA) is considered an advantageous technique for element determination of environmental contaminants, since it is a non-destructive technique, that requires minimal manipulation of the sample and provides low detection limits [4,5]. However, some elements are not determined with good accuracy by this technique, as in the case of $\mathrm{Hg}$.

In the analysis of $\mathrm{Hg}$ by INAA, two radioisotopes that can be measured for its quantification are formed: ${ }^{197} \mathrm{Hg}$ (77.34 keV with half-life of $\left.64.16 \mathrm{~h}\right)$ and ${ }^{203} \mathrm{Hg}(279.20 \mathrm{keV}$ with half-life of $46.61 \mathrm{~d})$ [6]. However, the main difficulty in the determination of $\mathrm{Hg}$ by INAA is the loss of this element during irradiation due to a combination of electrolytic action creating elemental $\mathrm{Hg}$, recoil due to the $(n, \gamma)$ reaction, and thermal heating [7]. The use of quartz ampoules as irradiation container would avoid the $\mathrm{Hg}$ loss [8], but it is not adequate due to the difficulty in transferring the irradiated sample from the ampoule to a counting container. In addition, the ampoule becomes quite radioactive due to the activation of the sodium present in it.

The aim of this study was to establish adequate conditions for $\mathrm{Hg}$ determination in environmental samples by INAA in IEA-R1 reactor. In order to obtain reliable results, the following experimental parameters were evaluated: irradiation time, type of container for sample irradiation and the problem of the spectral interferences. For this study, environmental certified reference materials and tree bark samples, used as environmental biomonitor, were analyzed.

\section{MATERIALS AND METHODS}




\subsection{Materials}

\subsubsection{Certified reference materials}

For quality control in relation to the precision and accuracy of the results, certified reference materials (CRMs) INCT M-4 CormTis Cormorant Tissue provided by Institute of Nuclear Chemistry and Technology, IAEA-085 Methylmercury, Total Mercury and Other Trace Elements in Human Hair provided by International Atomic Energy Agency, NRC DOLT-3 Dogfish Liver Certified Reference Material for Trace Metals provided by National Research Council Canada and BCR 186 Trace Elements in Lyophilised Pig Kidney provided by Community Bureau of Reference were analyzed.

Percentages of residual humidity of these CRMs were determined in order to obtain the results on dry basis. For this determination, approximately $250 \mathrm{mg}$ of each material were dried in a Universal oven at a temperature of $85^{\circ} \mathrm{C}$, for $24 \mathrm{~h}$. The percentages of humidity obtained in this drying process were $6.1 \%$ for CRM INCT M-4 Cormorant Tissue, $6.6 \%$ for IAEA-085 Human Hair, 14.5\% for NCR DOLT-3 Dogfish Liver and $5.7 \%$ for BCR 186 Pig Kidney.

\subsubsection{Environmental samples}

Tree bark samples of the species Poincianella pluviosa (Sibipiruna) and Tipuana tipu (Tipuana) were collected in several sites of São Paulo Metropolitan Region (SP, Brazil). The collection was carried out at a height from 1.5 to $2.5 \mathrm{~m}$ from topsoil using a stainless steel knife. When the bark was wet, it was previously dried at $40^{\circ} \mathrm{C}$ using an oven with forced air circulation. For the analyses, the samples were carefully cleaned using a dental brush with soft nylon bristles in order to remove the foreign materials and then the surface layer of the tree bark, with a thickness less than $3 \mathrm{~mm}$, was grated using a titanium grater. Finally, the samples were ground to a fine powder using a vibratory micro mill with an agate mortar (Vibratory Micro Mill Pulverisette 0, FRITSCH), and then placed in plastic vials that were stored in a desiccator.

Percentages of residual humidity of these powder bark samples, determined as described for CRMs, varied from 4.9 to $12.5 \%$.

\subsection{Procedure for Neutron Activation Analysis}

\subsubsection{Preparation of synthetic standard of mercury}


Certified standard solution of $\mathrm{Hg}$ acquired from Spex CertiPrep USA was used to prepare synthetic standard. From the stock standard solution, a diluted solution with $\mathrm{Hg}$ concentration of $136.5 \mu \mathrm{g}$ $\mathrm{mL}^{-1}$ was prepared. To avoid $\mathrm{Hg}$ loss in the synthetic standard, thioacetamide solution was also used. Thioacetamide minimizes $\mathrm{Hg}$ losses by volatilization, since the sulfur present in its structure reacts with $\mathrm{Hg}$, leading to the formation of $\mathrm{HgS}[9,10]$. A $7.8 \mathrm{mg} \mathrm{mL}^{-1}$ thioacetamide solution was prepared by dissolving $195.7 \mathrm{mg}$ of thioacetamide p.a. from Merck with purified water, and diluting to $25 \mathrm{~mL}$.

Aliquots of $50 \mu \mathrm{L}$ of thioacetamide solution were pipetted on each small sheet of $n^{\circ} .40$ Whatman filter paper with the size $1.5 \mathrm{~cm}$ x $6.0 \mathrm{~cm}$. The sheets were placed in a desiccator for drying the aliquots at room temperature. Then, aliquots $50 \mu \mathrm{L}$ of diluted $\mathrm{Hg}$ solution were pipetted on each sheet, which remained again in a desiccator for drying at room temperature. The sheets were folded and placed in plastic envelopes. The plastic (polyethylene) foils used to prepare these envelopes were previously cleaned using diluted nitric acid solution and purified water, and finally drying at room temperature. The micropipette used was previously checked in relation to its calibration.

To prepare Hg standard in the type W polyethylene capsule (Vrije Univesiteit, Amsterdam, The Nertherlands), a small sheet of $\mathrm{N}^{\circ} .40$ Whatman filter paper was cut and placed inside the capsule. Then, $50 \mu \mathrm{L}$ of thioacetamide solution were pipetted on the small sheet placed inside the capsule, which remained in a desiccator for drying at room temperature. After that, $50 \mu \mathrm{L}$ of $\mathrm{Hg}$ diluted standard solution were pippeted on this sheet, which remained again in a desiccator for drying at room temperature. The $\mathrm{Hg}$ synthetic standards were kept in a refrigerator until its use in the analyses.

\subsubsection{Irradiation, measurement and calculations}

Aliquots of each tree bark sample or certified reference material were weighted (150 to $200 \mathrm{mg}$ ) in polyethylene envelopes. Each envelope containing the sample or standard was wrapped with aluminum foil. This set of samples and standard was placed in an aluminum irradiation device called "rabbit". Irradiation was performed at the IEA-R1 nuclear research reactor for 1 or $8 \mathrm{~h}$, under a thermal neutron flux varying from $4.2 \times 10^{12} \mathrm{n} \mathrm{cm}^{2} \mathrm{~s}^{-1}$ to $4.6 \times 10^{12} \mathrm{n} \mathrm{cm}^{2} \mathrm{~s}^{-1}$.

In the case of irradiations using polyethylene capsules, aliquots (150-200 mg) of each material were weighed in the capsules, occupying about $2 / 3$ of the total volume of the capsule. Each capsule con- 
taining sample or standard was wrapped with aluminum foil and then the set of samples and standard was placed into the "rabbit".

After adequate decay time of $1 \mathrm{~d}$, for samples irradiated for $1 \mathrm{~h}$, and of $3 \mathrm{~d}$, for samples irradiated for $8 \mathrm{~h}$, samples and standard were placed individually in stainless steel planchets for gamma ray activity measurements. In the case of irradiations using polyethylene capsules, samples and standard were placed individually in plastic counting tubes.

The induced gamma ray activity measurements were carried out using a hyperpure germanium detector from Canberra (model GC3020) connected to a digital spectrum analyzer (model DSA 1000). The system used had a resolution (FWHM) of $0.90 \mathrm{keV}$ for $121.97 \mathrm{keV}$ peak of ${ }^{57} \mathrm{Co}$ and of 1.70 $\mathrm{keV}$ for $1332.49 \mathrm{keV}$ peak of ${ }^{60} \mathrm{Co}$. The analysis of gamma spectra was performed using the computer program Genie 2000, 3.1 version, also from Canberra. The photopeaks of two radioisotopes of $\mathrm{Hg}$ were measured at different decay times: $77.34 \mathrm{keV}$ of ${ }^{197} \mathrm{Hg}\left(\mathrm{t}_{1 / 2}=64.16 \mathrm{~h}\right)$ and $279.20 \mathrm{keV}$ of

${ }^{203} \mathrm{Hg}\left(\mathrm{t}_{1 / 2}=46.61 \mathrm{~d}\right)$. The counting times varied from 1800 to $5400 \mathrm{~s}$ for the standard, and from 3600 to $36000 \mathrm{~s}$ for the samples, depending on their activities. The calculations for obtaining $\mathrm{Hg}$ mass fraction were performed by comparative method [11].

\subsection{Treatment of data}

To evaluate the mass fraction results of $\mathrm{Hg}$ in the CRMs in relation to their accuracy and precision, the arithmetic mean of the results, standard deviation, relative standard deviation, HORRAT value, relative error and standardized difference ( $\mathrm{Z}$ score) were calculated. In addition, detection limits and quantification limits of $\mathrm{Hg}$ were obtained for the analyzed environmental samples of tree barks.

\subsubsection{Relative standard deviation and HORRAT value}

The precision of the results was evaluated according to Wood [12], who considers that this parameter is related to the level of concentration (or mass fraction) of the analyte in the sample and it is defined by the Horwitz equation [13] given by:

$$
\mathrm{RSD}_{\mathrm{H}}=2^{(1-0.5 \log \mathrm{c})}
$$


Where $\mathrm{RSD}_{\mathrm{H}}$ is the value of Horwitz and $\mathrm{c}$ is the analyte's mass fraction. The precision of the method was verified by the HORRAT value given by [12]:

$$
\text { HORRAT }=\frac{\text { RSD }}{\operatorname{RSD}_{\mathrm{H}}}
$$

Where RSD is the relative standard deviation obtained experimentally.

The method is considered precise when HORRAT $\leq 2$ [12].

\subsubsection{Standardized difference or $\mathbf{Z}$ score value}

To evaluate the accuracy of the CRMs results, $\mathrm{Z}$ score values were calculated using Equation 2, where $\mathrm{X}_{\text {lab }}$ is the mass fraction obtained in the laboratory, $\mathrm{X}_{\text {ref }}$, the mass fraction of the certificate and $\mathrm{SD}_{\mathrm{mod}}$, the modified standard deviation, obtained by Equation 3 [14].

$$
\mathrm{Z} \text { score }=\frac{\mathrm{X}_{\mathrm{lab}}-\mathrm{X}_{\mathrm{red}}}{\mathrm{SD}_{\mathrm{mod}}}
$$

$$
S D_{\text {mod }}=\sqrt{S D^{2}+u_{X r e f}^{2}}
$$

Where SD is the standard deviation of the measurements performed in the laboratory and $\mathrm{u}_{\mathrm{Xref}}$ is the combined uncertainty of the reference value of the certificate. The result is classified as satisfactory or unsatisfactory according to the following criteria [14]:

If $\mid \mathrm{Z}$ score $\mid \leq 2$, the result is considered satisfactory;

If $2<\mid \mathrm{Z}$ score $\mid<3$, the result is considered uncertain;

If $\mid \mathrm{Z}$ score $\mid \geq 3$, the result is considered unsatisfactory.

\subsubsection{Detection limits and quantification limits}

Detection limits and quantification limits were calculated using Currie's criterion [15], which defines the detection limit (DLT) and the quantification limit (QLT) as:

$$
\mathrm{DLT}=3.29 \frac{\sqrt{\mathrm{BG}}}{\mathrm{LT}}
$$

$$
\mathrm{QLT}=10 \frac{\sqrt{\mathrm{BG}}}{\mathrm{LT}}
$$

Where DLT and QLT are, respectively, detection limit and quantification limit in counting rates, BG is the background and LT is the counting time. Once the DLT and QLT values were obtained, 
the detection limits (DL) and quantification limits (QL) in element mass fraction were obtained by the comparative method.

\subsection{Preliminary Assays for Establishing Adequate Experimental Conditions}

\subsubsection{Analysis of $\mathrm{Hg}$ impurities in the polyethylene envelopes and in the $\mathrm{N}^{\circ}$. 40 Whatman fil-} ter paper sheets

To evaluate the presence of $\mathrm{Hg}$ in the polyethylene envelopes, used for sample irradiation, empty envelopes were analyzed using the same experimental conditions used in the sample analyses.

The same procedure used for determination of $\mathrm{Hg}$ in the polyethylene envelopes was applied for the analysis of the $\mathrm{N}^{\circ}$. 40 Whatman filter paper sheets, used as support in the preparation of synthetic standard. For this study, filter paper samples were cut in the same size as the sheets used for preparing the synthetic standard.

\subsubsection{Irradiation using different polyethylene containers for $\mathrm{Hg}$ determination}

To choose the most adequate container for irradiation in the $\mathrm{Hg}$ determination, aliquots of the CRM IAEA-085 Human Hair and $\mathrm{Hg}$ synthetic standard were irradiated for $1 \mathrm{~h}$ in polyethylene capsules and in polyethylene envelopes, in order to evaluate if there was $\mathrm{Hg}$ loss. Mercury losses during the irradiation were evaluated by comparing the $\mathrm{Hg}$ mass fractions obtained and the certified value. To evaluate $\mathrm{Hg}$ loss after the irradiation, gamma ray activities of the $\mathrm{Hg}$ standards were measured at different decay times and the counting rates obtained were correct to zero decay time, according to the law of radioactive decay (Equation 7) [16].

$$
A=A_{0} e^{\frac{-\ln 2}{t_{1}} t}
$$

Where $\mathrm{A}$ and $\mathrm{A}_{0}$ are the counting rates for decay times $\mathrm{t}$ and $\mathrm{t}=0$, respectively and $\mathrm{t}_{1 / 2}$ is the halflife.

\subsubsection{Selection of irradiation time}

Mercury losses during the irradiation were evaluated by comparing the $\mathrm{Hg}$ mass fractions obtained and the certified value. 
Aliquots of the CRM IAEA-085 Human Hair and Hg synthetic standard placed in polyethylene envelopes were irradiated for 1 and $8 \mathrm{~h}$ and the gamma ray activities were measured for different decay times. In order to evaluate the $\mathrm{Hg}$ loss after irradiation, the counting rates of $\mathrm{Hg}$ standard obtained for different decay time were corrected for zero decay time. The irradiated $\mathrm{Hg}$ standard was kept in the counting room at temperature of $20^{\circ} \mathrm{C}$ throughout the period in which the counts were performed.

\section{RESULTS AND DISCUSSION}

\subsection{Determination of $\mathrm{Hg}$ Impurities in the Polyethylene Envelopes and in the Filter Paper} Sheets

Mercury impurities in the polyethylene envelopes used in the irradiations were not detected, and detection limits of 0.007 and $0.10 \mu \mathrm{g}$ per envelope were obtained by measuring ${ }^{197} \mathrm{Hg}$ and ${ }^{203} \mathrm{Hg}$, respectively.

The determination of $\mathrm{Hg}$ impurity in the $\mathrm{N}^{\mathrm{o}}$. 40 Whatman filter paper sheet (used in the preparation of synthetic standard) indicated that this element is present at very low mass fractions. In the analysis of a filter paper sheet, measuring $1.5 \mathrm{~cm}$ x $6.0 \mathrm{~cm}$ and weighting $0.12030 \mathrm{~g}, \mathrm{Hg}$ mass fraction of $0.0702 \pm 0.0056 \mu \mathrm{g} \mathrm{g}^{-1}$ or a quantity of $0.0084 \mu \mathrm{g}$ per sheet was obtained. Since the $\mathrm{Hg}$ mass in the synthetic standard is $6.8 \mu \mathrm{g}$, the presence of this element in the filter paper sheet was considered negligible.

\subsection{Irradiation Using Different Kinds of Polyethylene Containers for $\mathbf{H g}$ Determination}

This study was carried out in order to choose a most adequate container for sample irradiation, avoiding $\mathrm{Hg}$ loss by volatilization. The $\mathrm{Hg}$ loss in the envelope and in the capsule during $1 \mathrm{~h}$ of irradiation was verified by the analysis of aliquots of the CRM IAEA-085 Human Hair, with certified value of $\mathrm{Hg}$ mass fraction of $23.2 \pm 0.8 \mu \mathrm{g} \mathrm{g}{ }^{-1}$ [17]. By measuring ${ }^{197} \mathrm{Hg}$ and ${ }^{203} \mathrm{Hg}$ for different decay times, results of $\mathrm{Hg}$ mass fraction were obtained, and they varied from $23.23 \pm 0.11$ to $26.75 \pm$ $0.40 \mu \mathrm{g} \mathrm{g}^{-1}$, for sample irradiated in polyethylene capsule, and from $23.58 \pm 0.14$ to $25.536 \pm 0.087$ $\mu \mathrm{g} \mathrm{g}^{-1}$, when polyethylene envelope was used. These results indicate that there were no $\mathrm{Hg}$ losses 
during the irradiations from both containers, since the obtained results for mass fraction are very close to the certified value.

The $\mathrm{Hg}$ loss after irradiation was also verified by measuring synthetic standard of $\mathrm{Hg}$ for different decay times. The counting rates obtained were corrected for the same decay time $(t=0)$ from the measurements obtained in different decay times. Tables 1 and 2 show the obtained results for $\mathrm{Hg}$ standard irradiated in polyethylene capsule and in polyethylene envelope, respectively. Counting rates with their respective uncertainties were obtained for the photopeaks of $77.34 \mathrm{keV}$ of ${ }^{197} \mathrm{Hg}$ and $279.20 \mathrm{keV}$ of ${ }^{203} \mathrm{Hg}$.

Table 1: Counting rates of $\mathrm{Hg}$ synthetic standard corrected $\left(\mathrm{A}_{0}\right)$ for decay time $\mathrm{t}_{0}=0$. Measurements obtained for different decay times. Irradiation time of $1 \mathrm{~h}$ in polyethylene capsule.

\begin{tabular}{ccc}
\hline $\begin{array}{c}\text { Decay times, } \\
\text { days }\end{array}$ & ${ }^{197} \mathbf{H g}, \mathbf{7 7 . 3 4} \mathbf{~ k e V}$ & ${ }^{{ }^{203} \mathbf{H g}, \mathbf{2 7 9 . 2 0 ~ k e V}}$ \\
\cline { 2 - 3 } & $\begin{array}{c}\mathbf{A}_{\mathbf{0}}, \\
\text { countings s }^{-1}\end{array}$ & $\begin{array}{c}\mathbf{A}_{\mathbf{0}}, \\
\text { countings s }\end{array}$ \\
\hline $\mathbf{5 . 9}$ & $108.30 \pm 0.27$ & $4.626 \pm 0.031$ \\
$\mathbf{7 . 0}$ & $108.44 \pm 0.31$ & $4.611 \pm 0.031$ \\
$\mathbf{8 . 9}$ & $109.77 \pm 0.41$ & $4.691 \pm 0.031$ \\
$\mathbf{1 1 . 0}$ & $108.07 \pm 0.75$ & $4.534 \pm 0.031$ \\
$\mathbf{1 1 . 9}$ & $108.95 \pm 0.60$ & $4.601 \pm 0.032$ \\
\hline
\end{tabular}

Table 2: Counting rates of $\mathrm{Hg}$ synthetic standard corrected $\left(\mathrm{A}_{0}\right)$ for decay time $\mathrm{t}_{0}=0$. Measurements obtained for different decay times. Irradiation time of $1 \mathrm{~h}$ in polyethylene envelope.

\begin{tabular}{ccc}
\hline $\begin{array}{c}\text { Decay times, } \\
\text { days }\end{array}$ & ${ }^{197} \mathbf{H g}, \mathbf{7 7 . 3 4} \mathbf{~ k e V}$ & ${ }^{{ }^{203} \mathbf{H g}, 279.20 ~ \mathbf{~ k e V}}$ \\
\cline { 2 - 3 } & $\begin{array}{c}\mathbf{A}_{\mathbf{0}}, \\
\text { countings s}\end{array}$ & $\begin{array}{c}\mathbf{A}_{\mathbf{0}}, \\
\text { countings s }\end{array}$ \\
\hline $\mathbf{5 . 7}$ & $116.78 \pm 0.28$ & $6.397 \pm 0.036$ \\
$\mathbf{6 . 9}$ & $120.15 \pm 0.32$ & $6.498 \pm 0.036$ \\
$\mathbf{8 . 9}$ & $120.75 \pm 0.42$ & $6.510 \pm 0.037$ \\
$\mathbf{9 . 9}$ & $91.93 \pm 0.42$ & $6.278 \pm 0.036$ \\
$\mathbf{1 3 . 9}$ & $121.39 \pm 0.84$ & $6.488 \pm 0.038$ \\
\hline
\end{tabular}


Results of Table 1 show that for the $\mathrm{Hg}$ standard irradiated in capsule, the values of the counting rates for the two photopeaks remained approximately constant until about $12 \mathrm{~d}$ of decay. In the case of the standard irradiation in polyethylene envelope (Table 2), the counting rates remained approximately constant until about $14 \mathrm{~d}$ of decay. These results indicate that, for decay times of up to $12 \mathrm{~d}$, there was no $\mathrm{Hg}$ loss after irradiation either from the capsule or from the envelope.

Based on these results, polyethylene envelopes were select for sample and standard irradiations for $\mathrm{Hg}$ determination due to its ease of acquisition and cheaper cost.

\subsection{Mercury Determination Using Different Irradiation Times}

The adequate irradiation time for $\mathrm{Hg}$ determination without causing its loss was chosen by analyzing the CRM IAEA-085 Human Hair, using irradiation times of 1 and $8 \mathrm{~h}$. Mercury mass fraction obtained with 1 and $8 \mathrm{~h}$ of irradiation, by measuring ${ }^{197} \mathrm{Hg}$ and ${ }^{203} \mathrm{Hg}$ for different decay times, presented good agreement with certified value $\left(23.2 \pm 0.8 \mu \mathrm{g} \mathrm{g}^{-1}\right)$ [17]. The results varied from $23.58 \pm$ 0.14 to $25.536 \pm 0.087 \mu \mathrm{g} \mathrm{g}^{-1}$, for sample irradiated for $1 \mathrm{~h}$, and from $25.311 \pm 0.020$ to $25.316 \pm$ $0.034 \mu \mathrm{g} \mathrm{g}^{-1}$, for that irradiated for $8 \mathrm{~h}$. These results indicate that there were no $\mathrm{Hg}$ losses during the irradiation, since the obtained values of mass fraction are close to the certified value. However, after decay of ${ }^{24} \mathrm{Na}$ in the sample, the radionuclide ${ }^{75} \mathrm{Se}$ was identified in the CRM IAEA-085 Human Hair irradiated for $8 \mathrm{~h}$, becoming impossible to determine $\mathrm{Hg}$ by measuring ${ }^{203} \mathrm{Hg}$, since the gamma ray energies emitted by ${ }^{75} \mathrm{Se}$ and by ${ }^{203} \mathrm{Hg}$ are very close to each other $(279.93 \mathrm{keV}$ and $279.20 \mathrm{keV}$, respectively) [6]. Besides using the irradiation of $8 \mathrm{~h}$ for CRM IAEA-085 Human Hair, a complex gamma ray spectrum was obtained in the region of low energy with high counting rates at of $68.89 \mathrm{keV}$ and $411.80 \mathrm{keV}$ of ${ }^{198} \mathrm{Au}$. According to Zmijewsk [8], an important interference in $\mathrm{Hg}$ determination by INAA is that of ${ }^{198} \mathrm{Au}$, whose photopeaks of energies 70.8 and $80.3 \mathrm{keV}$ are not resolved from ${ }^{197} \mathrm{Hg}$ photopeak. The interference of ${ }^{198} \mathrm{Au}$ in the $77.34 \mathrm{keV}$ photopeak of ${ }^{197} \mathrm{Hg}$ could not be verified by determining half-life, since these two radionuclides present very close halflifes (64.16 $\mathrm{h}$ for ${ }^{197} \mathrm{Hg}$ and $64.80 \mathrm{~h}$ for $\left.{ }^{198} \mathrm{Au}\right)$ [6].

Table 3 shows the results obtained in the study of $\mathrm{Hg}$ loss after irradiation for $\mathrm{Hg}$ standard irradiated for $8 \mathrm{~h}$ in polyethylene envelope. The counting rates with their respective uncertainties corrected for decay time $\mathrm{t}_{0}=0$ were obtained for the photopeaks of $77.34 \mathrm{keV}$ of ${ }^{197} \mathrm{Hg}$ and $279.20 \mathrm{keV}$ of 
${ }^{203} \mathrm{Hg}$. This table shows that the counting rates calculated for zero decay time remained approximately constant until about $14 \mathrm{~d}$ of decay, indicating no loss of $\mathrm{Hg}$ after irradiation.

Table 3: Counting rates of $\mathrm{Hg}$ synthetic standard corrected $\left(\mathrm{A}_{0}\right)$ for decay time $\mathrm{t}_{0}=0$. Measurements obtained for different decay times. Irradiation time of $8 \mathrm{~h}$ in polyethylene envelope.

\begin{tabular}{ccc}
\hline $\begin{array}{c}\text { Decay times, } \\
\text { days }\end{array}$ & $\begin{array}{c}{ }^{197} \mathbf{H g}, \mathbf{7 7 . 3 4} \\
\mathbf{k e V}\end{array}$ & $\begin{array}{c}{ }^{203} \mathbf{H g}, \mathbf{2 7 9 . 2 0} \\
\mathbf{k e V}\end{array}$ \\
\cline { 2 - 3 } & $\begin{array}{c}\mathbf{A}_{\mathbf{0}}, \\
\text { countings s}^{-1}\end{array}$ & $\begin{array}{c}\mathbf{A}_{\mathbf{0}}, \\
\text { countings s }^{-1}\end{array}$ \\
\hline $\mathbf{6 . 9}$ & $716.27 \pm 0.86$ & $38.140 \pm 0.092$ \\
$\mathbf{9 . 1}$ & $711.1 \pm 1.1$ & $37.266 \pm 0.089$ \\
$\mathbf{1 0 . 0}$ & $719.0 \pm 1.9$ & $37.51 \pm 0.21$ \\
$\mathbf{1 4 . 0}$ & $722.9 \pm 2.2$ & $37.793 \pm 0.094$ \\
\hline
\end{tabular}

Based on the obtained results, irradiation time of $1 \mathrm{~h}$ was chosen, in order to avoid gamma ray spectral interferences from ${ }^{198} \mathrm{Au}$ and ${ }^{75} \mathrm{Se}$.

\subsection{Analyses of Certified Reference Materials and of Environmental Samples}

Tables 4 to 7 show the results obtained in the analyses of certified reference materials NCR DOLT3 Dogfish Liver, BCR 186 Pig Kidney, INCT M-4 Cormorant Tissue and IAEA-085 Human Hair, respectively. In these Tables, results are presented for different decay times used for counting. For CRMs NCR DOLT-3 Dogfish Liver, BCR 186 Pig Kidney and INCT M-4 Cormorant Tissue, it was observed that determinations performed after $4 \mathrm{~d}$ of decay presented higher values of relative standard deviation and relative error, probably due to the high activity of ${ }^{24} \mathrm{Na}\left(\mathrm{t}_{1 / 2}=14.96 \mathrm{~h}\right)$ that masked the less intense activities of ${ }^{197} \mathrm{Hg}$. All the obtained results presented satisfactory values of relative error, HORRAT value and $\mathrm{Z}$ score for all the materials, except for the measurement of the ${ }^{197} \mathrm{Hg}$ photopeak for $2 \mathrm{~d}$ of decay in CRM BCR 186 Pig Kidney, in which it was obtained Z score > 
2. For CRMs NCR DOLT-3 Dogfish Liver and BCR 186 Pig Kidney, Hg was not determined by measuring ${ }^{203} \mathrm{Hg}$, since ${ }^{75} \mathrm{Se}$ was identified in the spectra of these materials.

Mercury was not detected in the tree bark samples analyzed in this study, so detection limits and quantification limits for $\mathrm{Hg}$ determinations were calculated by the measurement of ${ }^{197} \mathrm{Hg}$ and ${ }^{203} \mathrm{Hg}$ radionuclides (Table 8). The bark samples analyzed were probably not collected in regions polluted by $\mathrm{Hg}$ emission into the atmosphere. According to Martín et al [21], this element is naturally present in the environment at very low concentrations ( 0.005 to $0.06 \mathrm{ng} \mathrm{m}^{-3}$ in air). Results showed in Table 8 indicate that detection limits obtained for ${ }^{197} \mathrm{Hg}$ gamma ray peak are lower than those obtained for ${ }^{203} \mathrm{Hg}$.

Table 4: Mass fractions of Hg obtained in the CRM NCR DOLT-3 Dogfish Liver by measuring the ${ }^{197} \mathrm{Hg}$ radioisotope. Results obtained for different decay times used for counting.

\begin{tabular}{|c|c|c|c|c|}
\hline \multirow{3}{*}{$\begin{array}{c}\text { Evaluated } \\
\text { parameters }^{\text {a }}\end{array}$} & \multicolumn{3}{|c|}{ Results obtained in this study, $\mu \mathrm{g} \mathrm{g}^{-1}$} & \multirow{3}{*}{$\begin{array}{c}\text { Certified value, } \\
\mu^{\mu g ~ g^{-1}}[18]\end{array}$} \\
\hline & \multicolumn{3}{|c|}{${ }^{197} \mathrm{Hg}, 77.34 \mathrm{keV}$} & \\
\hline & $\mathrm{dt}^{\mathrm{b}}=4 \mathrm{~d}$ & $\mathrm{dt}=5 \mathrm{~d}$ & $\mathrm{dt}=6 \mathrm{~d}$ & \\
\hline$X \pm S D(n)$ & $3.10 \pm 0.36(4)$ & $3.18 \pm 0.20(4)$ & $3.65 \pm 0.24(4)$ & $3.37 \pm 0.14$ \\
\hline RSD, \% & 11.4 & 6.4 & 6.5 & \\
\hline HORRAT & 0.59 & 0.48 & 0.49 & \\
\hline RE, \% & 8.0 & 5.6 & 8.3 & \\
\hline$Z$ score & -0.74 & -0.87 & 1.1 & \\
\hline
\end{tabular}

a. X \pm SD: Arithmetic mean and standard deviation; $n$ : number of determinations; RSD: relative standard deviation; RE: relative error; $\mathrm{b}$. $\mathrm{dt}=$ decay time.

Table 5: Mass fractions of $\mathrm{Hg}$ obtained in the CRM BCR 186 Pig Kidney by measuring the ${ }^{197} \mathrm{Hg}$ radioisotope. Results obtained for different decay times used for counting.

\begin{tabular}{|c|c|c|c|c|}
\hline \multirow{3}{*}{$\begin{array}{c}\text { Evaluated } \\
\text { parameters }^{\mathrm{a}}\end{array}$} & \multicolumn{3}{|c|}{ Results obtained in this study, $\mu \mathrm{g} \mathrm{g}^{-1}$} & \multirow{3}{*}{$\begin{array}{c}\text { Certified value, } \\
\qquad \mu \mathrm{g} \mathrm{g}^{-1}[19]\end{array}$} \\
\hline & \multicolumn{3}{|c|}{${ }^{197} \mathrm{Hg}, 77.34 \mathrm{keV}$} & \\
\hline & $\mathrm{dt}^{\mathrm{b}}=4 \mathrm{~d}$ & $d t=5 d$ & $d t=6 d$ & \\
\hline$X \pm S D(n)$ & $1.58 \pm 0.27(4)$ & $1.65 \pm 0.13(4)$ & $1.78 \pm 0.16(4)$ & $1.97 \pm 0.04$ \\
\hline RSD, \% & 17.1 & 8.2 & 9.3 & \\
\hline HORRAT & 1.1 & 0.55 & 0.63 & \\
\hline RE, \% & 19.9 & 16.1 & 2.7 & \\
\hline $\mathrm{Z}$ score & -1.5 & -2.3 & -1.2 & \\
\hline
\end{tabular}

a. $\mathrm{X} \pm$ SD: Arithmetic mean and standard deviation; $n$ : number of determinations; RSD: relative standard deviation; RE: relative error; $b . \mathrm{dt}=$ decay time. 
Table 6: Mass fractions of Hg obtained in the CRM INCT M-4 Cormorant Tissue by measuring the ${ }^{197} \mathrm{Hg}$ and ${ }^{203} \mathrm{Hg}$ radioiso-

\begin{tabular}{|c|c|c|c|c|c|c|c|}
\hline \multirow{3}{*}{$\begin{array}{c}\text { Evaluated } \\
\text { parameters }\end{array}$} & \multicolumn{6}{|c|}{ Results obtained in this study, $\mu \mathrm{g} \mathrm{g}_{\mathrm{g}}^{-1}$} & \multirow{3}{*}{$\begin{array}{c}\text { Certified } \\
\text { value, } \\
{\mu \mathrm{g} \mathrm{g}^{-1}}^{2}[20]\end{array}$} \\
\hline & \multicolumn{3}{|c|}{${ }^{197} \mathrm{Hg}, 77.34 \mathrm{keV}$} & \multicolumn{3}{|c|}{${ }_{203} \mathrm{Hg}, 279.20 \mathrm{keV}$} & \\
\hline & $\mathrm{dt}^{\mathrm{b}}=4 \mathrm{~d}$ & $\mathrm{dt}=5 \mathrm{~d}$ & $\mathrm{dt}=6 \mathrm{~d}$ & $\mathrm{dt}=4 \mathrm{~d}$ & $d t=5 d$ & $\mathrm{dt}=6 \mathrm{~d}$ & \\
\hline$X \pm S D(n)$ & $1.89 \pm 0.24(4)$ & $2.05 \pm 0.11(4)$ & $2.13 \pm 0.11(4)$ & $1.82 \pm 0.33(4)$ & $2.10 \pm 0.34(4)$ & $2.30 \pm 0.23(4)$ & $2.20 \pm 0.14$ \\
\hline RSD, \% & 12.6 & 5.2 & 5.1 & 18.1 & 16.1 & 10.0 & \\
\hline HORRAT & 0.87 & 0.36 & 0.36 & 1.2 & 1.1 & 0.71 & \\
\hline RE, \% & 14.2 & 6.7 & 3.1 & 17.2 & 4.6 & 4.3 & \\
\hline Z score & 1.2 & 1.1 & 0.53 & 1.1 & 0.30 & -0.40 & \\
\hline
\end{tabular}

topes. Results obtained for different decay times used for counting.

a. $\mathrm{X} \pm \mathrm{SD}$ : Arithmetic mean and standard deviation; n: number of determinations; RSD: relative standard deviation; RE: relative error. $\mathrm{b}$. $\mathrm{dt}=$ decay time.

Table 7: Mass fractions of $\mathrm{Hg}$ obtained in the CRM IAEA-085 Human Hair by measuring the ${ }^{197} \mathrm{Hg}$ and ${ }^{203} \mathrm{Hg}$ radioisotopes. Results obtained for different decay times used for counting.

\begin{tabular}{|c|c|c|c|c|c|c|c|}
\hline \multirow{3}{*}{$\begin{array}{c}\text { Evaluated } \\
\text { parameters }^{\text {a }}\end{array}$} & \multicolumn{6}{|c|}{ Results obtained in this study, $\mu \mathrm{g} \mathrm{g}^{-1}$} & \multirow{3}{*}{$\begin{array}{c}\text { Certified } \\
\text { value, } \\
\mu^{-1} \mathrm{~g}^{-1}[17]\end{array}$} \\
\hline & \multicolumn{3}{|c|}{${ }^{197} \mathrm{Hg}, 77.34 \mathrm{keV}$} & \multicolumn{3}{|c|}{${ }^{203} \mathrm{Hg}, 279.20 \mathrm{keV}$} & \\
\hline & $\mathbf{d t}^{\mathrm{b}}=\mathbf{1} \mathrm{d}$ & $\mathbf{d t}=\mathbf{2 d}$ & $\mathrm{dt}=\mathbf{5} \mathrm{d}$ & $\mathbf{d t}=\mathbf{1} \mathbf{d}$ & $\mathbf{d t}=\mathbf{2} \mathbf{d}$ & $\mathrm{dt}=\mathbf{5} \mathrm{d}$ & \\
\hline$X \pm S D(n)$ & $24.1 \pm 1.4(4)$ & $23.8 \pm 2.1(4)$ & $24.7 \pm 2.7(4)$ & $24.9 \pm 1.8(4)$ & $24.9 \pm 2.4(4)$ & $25.0 \pm 1.9(4)$ & $23.2 \pm 0.8$ \\
\hline RSD, \% & 5.6 & 8.8 & 11.1 & 7.3 & 9.5 & 7.6 & \\
\hline HORRAT & 0.57 & 0.89 & 1.1 & 0.74 & 0.96 & 0.77 & \\
\hline RE, \% & 4.1 & 2.5 & 6.5 & 7.2 & 7.2 & 7.9 & \\
\hline$Z$ score & -0.27 & -0.15 & -0.36 & -0.45 & -0.41 & -0.49 & \\
\hline
\end{tabular}

a. X \pm SD: Arithmetic mean and standard deviation; n: number of determinations; RSD: relative standard deviation; RE: relative error. $\mathrm{b}$. $\mathrm{dt}=$ decay time. 
Table 8: Detection limits (DL) and quantification limits (QL) of $\mathrm{Hg}$ obtained in the analysis of the tree bark samples

\begin{tabular}{|c|c|c|c|}
\hline Sample code ${ }^{a}$ & Radioisotope & $\begin{array}{c}\text { DL, } \\
\mu \mathrm{g} \mathrm{g}^{-1}\end{array}$ & $\begin{array}{c}\text { QL, } \\
\mu \mathrm{g} \mathrm{g}^{-1}\end{array}$ \\
\hline \multirow[b]{2}{*}{ A1 } & ${ }^{197} \mathrm{Hg}$ & 0.07 & 0.22 \\
\hline & ${ }^{203} \mathrm{Hg}$ & 0.7 & 2.1 \\
\hline \multirow[b]{2}{*}{ A2 } & ${ }^{197} \mathrm{Hg}$ & 0.08 & 0.24 \\
\hline & ${ }^{203} \mathrm{Hg}$ & 0.8 & 2.3 \\
\hline \multirow[b]{2}{*}{ A3 } & ${ }^{197} \mathrm{Hg}$ & 0.14 & 0.42 \\
\hline & ${ }^{203} \mathrm{Hg}$ & 1.9 & 5.8 \\
\hline \multirow[b]{2}{*}{ A4 } & ${ }^{197} \mathrm{Hg}$ & 0.1 & 0.3 \\
\hline & ${ }^{203} \mathrm{Hg}$ & 1.6 & 4.8 \\
\hline \multirow[b]{2}{*}{ A5 } & ${ }^{197} \mathrm{Hg}$ & 0.07 & 0.22 \\
\hline & ${ }^{203} \mathrm{Hg}$ & 1.0 & 3.0 \\
\hline \multirow[b]{2}{*}{ A6 } & ${ }^{197} \mathrm{Hg}$ & 0.1 & 0.3 \\
\hline & ${ }^{203} \mathrm{Hg}$ & 1.4 & 4.3 \\
\hline
\end{tabular}

${ }^{\text {a }}$ Samples coded A1 to A5 are from Tipuana tipu (Tipuana) specie. and A6, from Poincianella pluviosa (Sibipiruna) species.

\section{CONCLUSION}

From the results obtained in the analyses of polyethylene envelope and of the $\mathrm{N}^{\circ}$. 40 Whatman filter paper sheet, it can be concluded that $\mathrm{Hg}$ is present in these materials at very low levels and it was considered negligible in the analyses.

Results obtained using different containers for irradiation demonstrated that polyethylene capsules and polyethylene envelopes can be used for $\mathrm{Hg}$ determination by INAA. Both containers showed no $\mathrm{Hg}$ loss. In this study, polyethylene envelope was chosen due to its ease of acquisition and cheaper cost. 
Irradiation time of $1 \mathrm{~h}$ was chosen due to the problem of gamma ray spectral interference of ${ }^{198} \mathrm{Au}$ and ${ }^{75} \mathrm{Se}$ radionuclides. In addition, high activities of ${ }^{24} \mathrm{Na}$, formed by the longer irradiation time, may affect the results of $\mathrm{Hg}$ determinations. The high activity of ${ }^{24} \mathrm{Na}$ masked the less intense activities of ${ }^{197} \mathrm{Hg}$. The decay time of $6 \mathrm{~d}$, in general, presented more precise and accurate results.

The results obtained for certified reference materials indicated good agreement with the certificate values, demonstrating the accuracy of the data. Results obtained also presented good precision and accuracy, evaluated by the HORRAT values (HORRAT < 2), and by Z score obtained values ( $\mathrm{Z}$ score $\mid<2$ ). The exception was for $\mathrm{Hg}$ determination in the analysis of CRM BCR 186 Pig Kidney using decay time of $5 \mathrm{~d}$.

Mercury was not detected in tree bark samples. The detection limits obtained for tree bark analysis varied from 0.07 and $1.9 \mu \mathrm{g} \mathrm{g}^{-1}$, and the quantification limits were between 0.22 and $5.8 \mu \mathrm{g} \mathrm{g}^{-1}$. Results obtained for $\mathrm{Hg}$ determination in tree barks indicated that there is no emission source of this element in the region where they were collected.

\section{ACKNOWLEDGMENTS}

Authors thank Fundação de Amparo à Pesquisa do Estado de São Paulo (FAPESP) and Conselho Nacional de Desenvolvimento Científico e Tecnológico (CNPq) for financial support. In addition, C. Perez and E.C. Santos are grateful for scholarships from Comissão Nacional de Energia Nuclear (CNEN) and Coordenação de Aperfeiçoamento de Pessoal de Nível Superior (CAPES), respectively.

\section{REFERENCES}

1. YANG, J.; ZHAO, Y.; ZHANG, J.; ZHENG, C. Removal of elemental mercury from flue gas by recyclable $\mathrm{CuCl}_{2}$ modified magnetospheres catalyst from fly ash. Part 1. Catalyst characterization and performance evaluation. Fuel, v. 164, p. 419-428, 2016. 
2. DRASCH, G. A., Handbook on metals in clinical and analytical chemistry, $1^{\text {st }}$ edition. New York: Marcel Dekker, Inc., 1994.

3. S̆PIRIĆ, Z.; VUČKOVIĆ, I.; STAFILOV, T.; KUŠAN, V.; BAČEVA, K. Biomonitoring of air pollution with mercury in Croatia by using moss species and CV-AAS. Environmental Monitoring and Assessment, v. 186(7), p. 4357-4366, 2014.

4. BEDREGAL, P. S.; MENDOZA, P. A.; UBILlUS, M. S.; COHEN, I. M.; MONTOYA, E. $\mathrm{H}$. The $\mathrm{k} 0$ and relative INAA methods to determine elements in entire archaeological pottery objects. Journal of Radioanalytical and Nuclear Chemistry, v. 300, n. 2, p. 673-678, 2014.

5. AlmeIDA, S. M.; RAMOS, C. A.; MARQUES, A. M.; SILVA, A. V.; FREITAS, M. C.; FARINHA, M. M.; REIS M.; MARQUES, A. P. Use of INAA and PIXE for multipollutant air quality assessment and management. Journal of Radioanalytical and Nuclear Chemistry, v.294, n. 3, p 343-347, 2012.

6. IAEA. INTERNATIONAL ATOMIC ENERGY AGENCY. Practical aspects of operating a neutron activation analysis laboratory, IAEA-TEC-DOC-564, 1990.

7. ANDERSON, D. L. Use of l-cysteine for minimization of inorganic Hg loss during thermal neutron irradiation. Journal of Radioanalytical and Nuclear Chemistry, v. 282, n. 1, p. $11-14,2009$.

8. ŻMIJEWSKA, W. Activation analysis of mercury in environmental samples. Journal of Radioanalytical and Nuclear Chemistry, v. 35, n. 2, p. 389-418, 1977.

9. TAKEUCHI, T.; SHINOGI, M.; MORI, I. Volatilization losses of mercury in neutron activation analysis. Journal of Radioanalytical Chemistry, v. 53, p. 81-88, 1979.

10. PATTERSON, J. W.; PASSINO, R. Metals speciation separation and recovery (Vol. 1), $1^{\text {st }}$ edition. Chicago: CRC Press, 1987.

11. DE SOETE, D.; GILBELS, R.; HOSTE, J. Neutron activation analysis, $1^{\text {st }}$ edition, New York: Wiley-Interscience, 1972.

12. WOOD, R. How to validate analytical methods. Trends in Analytical Chemistry, v. 18, p. 624-632, 1999. 
13. HORWITZ W.; ALBERT, R. The Horwitz ratio (HorRat): A useful index of method performance with respect to precision. Journal of AOAC International, v. 89, n. 4, p. 1095 1109, 2006.

14. KONIECZKA, P.; NAMIESNIK, J. Quality assurance and quality control in the analytical chemical laboratory: a practical approach, $2^{\text {nd }}$ edition. Boca Raton: CRC Press, 2016.

15. CURRIE, L.A. International recommendations offered on analytical detection and quantification concepts and nomenclature. Analytica Chimica Acta, v.391, p.127-134, 1999.

16. FRIEDLANDER, G.; KENNEDY, J. W.; MILLER, J. M., Nuclear and radiochemistry, 2nd edition. London: John Wiley \& Sons, p. 6, 1964.

17. IAEA. INTERNATIONAL ATOMIC ENERGY AGENCY. Reference sheet, IAEA-085, Methylmercury, total mercury and other trace elements in human hair, 2000.

18. NCR. NATIONAL RESEARCH COUNCIL CANADA. Certificate of analysis, DOLT-3, Dogfish Liver Certified Reference Material for Trace Metals, 2002.

19. BCR. COMMUNITY BUREAU OF REFERENCE. Certificate of analysis, BCR 186, Trace elements in lyophilized pig kidney, 1986.

20. INCT. INSTITUTE OF NUCLEAR CHEMISTRY AND TECHNOLOGY. Certificate of analysis, MODAS-4 Cormorant Tissue, M-1 CormTis, 2015.

21. MARTín, J. A. R.; NANOS, N.; MIRANDA, J. C.; CARBONELL, G.; GIL, L. Volcanic mercury in Pinus canariensis. Naturwissenschaften, v. 100, n. 8, p. 739-747, 2013. 